\title{
Steps to be considered in the unsuccessful endoscopic retrograde cholangiopancreatography pre-criteria: Early pre-cut intervention. A retrospective cohort study
}

\author{
Mehlika Bilgi Kırmacı, ${ }^{1}$ (i) Tamer Akay, ${ }^{2}$ (D) Sezgin Yılmaz' \\ 'Department of General Surgery, Afyon Health Sciences University Medical Faculty Hospital, Afyon, Turkey \\ ${ }^{2}$ Department of General Surgery, Bandırma State Hospital, Balıkesir, Turkey
}

\begin{abstract}
Introduction: Endoscopic retrograde cholangiopancreatography (ERCP) is a widely used procedure for the treatment of several hepatobiliary and pancreatic diseases and also for diagnostic purposes of rare conditions. Despite advances in endoscopic accessories, selective biliary cannulation fails in $5-15 \%$ of cases, even in expert high-volume centers. However, there is still no consensus regarding the clinical outcomes of failed ERCP patients who underwent precut sphincterotomy. In the current work, we present the therapeutic approach and the outcomes of our patients with failed ERCP due to several reasons.
\end{abstract}

Materials and Methods: There were 1986 patients who were referred from another center due to primary ERCP requirement $(n=1862)$ or unsuccessful attempts to study at the primary center $(n=124)$. If the papilla has prerequisite criteria for failed ERCP, then the procedure was begun directly with precut incision.

Results: The ERCP procedure was successfully performed in all 1794 patients using a classic cannulation procedure. Pre-cut sphincterotomy method was successfully performed in 160 patients. There were 123 patients diagnosed by ERCP in our center and 103 of them were cannulated successfully with pre-cut sphincterotomy method. Pancreatitis developed in 12 of the 1794 patients $(0.66 \%)$ whose primary cannulation was successful. However, only two of the 160 patients $(1.25 \%)$ who underwent precut sphincterotomy developed pancreatitis postoperatively. One of these two patients had undergone unsuccessful precut trials.

Conclusion: The cannulation rate depends on the experience, the referral center where the procedure is carried out, the anatomical structure of the papilla, the indication necessitating the ERCP, and also the use of precut incision. In cannulation failure, patients should be directed to experienced, high-volume, and tertiary centers. In patients with failed ERCP pre-criteria, intervention should be initiated with the liberal use of the precut method. In unsuccessful cannulation, a 3-day waiting period reduces complications.

Keywords: Cannulation, endoscopic retrograde cholangiopancreatography, pancreatitis, pre-cut

\section{Introduction}

Endoscopic retrograde cholangiopancreatography (ERCP) is a widely used procedure for the treatment of several hepatobiliary and pancreatic diseases and also for diag- nostic purposes of rare conditions. ${ }^{[1]}$ Although there is a complication rate of up to $10 \%$, ERCP is still the basic instrument for endoscopists to diagnose and treat several diseases. ${ }^{[2]}$ The selective cannulation of the bile duct is the

Received: 12.02.2021 Accepted: 24.03.2021

Correspondence: Tamer Akay, M.D., Department of General Surgery,

Bandırma State Hospital, Balıkesir, Turkey

e-mail: op.dr.tamerakay@gmail.com 
main step for a successful ERCP and also a prerequisite to get maximum benefit. Despite the advances and new developments in endoscopic accessories such as catheters, guidewire, stents, and sphincterotomes, and selective biliary cannulation fails in $5-15 \%$ of cases, even in expert high-volume centers. ${ }^{[3]}$ Repeating ERCP within a few days after the initial unsuccessful precut is a successful strategy and should be attempted before contemplating more invasive, alternative interventions, such as percutaneous-endoscopic or endoscopic ultrasound-guided rendezvous procedure, percutaneous transhepatic, or surgical intervention. ${ }^{[4-10]}$

However, there is still no consensus regarding the clinical outcomes of failed ERCP patients who underwent precut sphincterotomy. In the current work, we present the therapeutic approach and the outcomes of our patients with failed ERCP due to several reasons.

\section{Materials and Methods}

\section{Patients}

Our hospital is a tertiary center in which $500-600$ cases are treated annually. So far, we have performed a total volume of nearly 5700 ERCP procedures for 10 years in our invasive endoscopy unit. Some nearby hospitals refer patients to our center for the primary ERCP procedure or after a failed ERCP procedure (with/without precut trials). First, the previous ERCP is evaluated, then, the requirement for further attempts and possible alternatives are decided.

The present study is a retrospective cohort study demonstrating the data of the patients in whom the ERCP procedure failed from January 2015 to April 2020. There were 1986 patients who were referred to our hospital from another center for primary ERCP requirement $(\mathrm{n}=1862)$ or unsuccessful attempts at the primary center $(n=124)$. There was no indication for ERCP in 31 patients who were admitted for primary cannulation and in one patient who was referred for failed cannulation. They were treated with medical therapy without the requirement for ERCP procedure. ERCP was not successful in 37 patients $(2.02 \%)$ who underwent primary cannulation. Therefore, the study included the results of 160 patients with failed primary cannulation.

The patients in whom the papilla could not be reached due to any reason (pyloric stenosis, altered gastric anatomy, duodenal obstruction due to tumor, etc.) and the pa- tients under 18 years of age were excluded from the study. Written informed consent was obtained from all subjects.

\section{Technical Set-up}

The procedures were performed using the side-viewing duodenoscopy system (Fujinon system, XL-Japan), and synchronous imaging techniques were obtained to confirm the location of the bile duct (Toshiba E5764SD-P4A, Medison X-ray, Korea). An anesthetist provided the sedation using ketamine, midazolam, and propofol (2, 6-diisopropylphenol) when the patients were in the left lateral decubitus position and regulated the sedation depending on the patient's alertness.

In the second attempt, the ERCP procedure was initiated using one of the two methods depending on the features of the papilla. If the papilla had an indication for failed ERCP, then the procedure was initiated directly with a precut incision. We proposed a modified technique and certain steps while making the precut to achieve maximum benefit. The technical details are mentioned in the previous section.

All methods were used in accordance with the relevant guidelines and regulations. All experimental protocols were approved by an institutional and/or licensing committee. Ethics committee approval was received from Afyon Health Sciences University Faculty of Medicine Ethics Committee on February 5, 2021, with the code 2011KAEK-2.

The procedure was initiated with the classical approach briefly using standard sphincterotome and guidewire for other cases in which the papilla had a normal appearance. If the cannulation could not be achieved in spite of the techniques mentioned above after a reasonable time, the case was defined as "failed" and abandoned. We checked the indications and the requirement for the procedure of the patient and repeated the ERCP procedure after 3 days following the first attempt. If the second attempt also failed, surgical procedures were then performed.

\section{Results}

This study presents the data of patients with failed ERCP procedure between January 2015 and April 2020. One thousand and nine hundred and eighty-six patients were referred from another center to our hospital for primary ERCP requirement $(n=1862)$ or unsuccessful attempts at the primary center $(n=124)$. There was no indication for 
ERCP in 31 patients who were admitted for primary cannulation and in one patient who was referred for failed cannulation. They were treated with medical therapy without the requirement for the ERCP procedure. ERCP was not successful in 37 patients (2.02\%) who underwent primary cannulation.

One hundred and twenty-three patients who could not be intervened at the primary center and 37 patients in whom primary cannulation failed were included in the study. Therefore, the results of a total of 160 patients with failed cannulation were included in the study. There were 94 female patients (58\%) and 66 male patients (42\%) with a female-to-male ration of 1.4:1. The median patient age was 77 years at the time of the index ERCP (range 46-95 years). The most common indications were common bile duct (CBD) stones or bile duct obstruction caused by malignancy (Table 1).

The ERCP procedure was successfully performed on all 1794 patients using the classic cannulation procedure. The precut sphincterotomy method was successfully performed on 160 patients. One out of 37 patients who had undergone prior sphincterotomy was operated for bleeding, and trans-duodenal sphincterotomy was performed.

One hundred and twenty-three patients in whom cannulation failed were referred to our center, 81 of whom underwent precut sphincterotomy. There were 123 patients diagnosed by ERCP in our center, 103 of whom were

Table 1. Indications or working diagnosis of 160 ERCP patients with pre-cut technique

\begin{tabular}{|c|c|c|}
\hline Indication or work-up diagnosis & $\mathbf{n}$ & $\%$ \\
\hline CBD stone & 54 & 33.75 \\
\hline Malignancy ${ }^{1}$ & 34 & 21.25 \\
\hline $\begin{array}{l}\text { Bile duct obstruction or jaundice } \\
\text { without accurate diagnosis }\end{array}$ & 31 & 19.37 \\
\hline Acute biliary pancreatitis & 9 & 5.62 \\
\hline Acute cholangitis & 11 & 6.87 \\
\hline Chronic pancreatitis & 6 & 3.75 \\
\hline Dysfunction of sphincter of Oddi & 3 & 1.87 \\
\hline Bile leak after cholecystectomy & 2 & 1.25 \\
\hline Other benign disease ${ }^{2}$ & 10 & 6.25 \\
\hline \multicolumn{3}{|c|}{$\begin{array}{l}\text { 1:Pancreatic cancer or papillary cancer, liver metastasis or } \\
\text { hepatocellular cancer, cancer of biliary tract or gallbladder; } 2 \text { :Pri- } \\
\text { mary sclerosing cholangitis, papillary tumor or polyp, bile duct } \\
\text { obstruction after cholecystectomy, primary biliary cirrhosis, cyst } \\
\text { of CBD. }\end{array}$} \\
\hline
\end{tabular}

cannulated successfully with the precut sphincterotomy method. Successful cannulation was performed by precut sphincterotomy in all patients in whom cannulation failed without a precut. We failed in 15 patients in the precut group, and the procedures were repeated 3 days later. Five out of 15 patients were not successfully cannulated at the second attempt. Three of these five patients had facet stones reaching $2-2.5 \mathrm{~cm}$ in the $\mathrm{CBD}$. These patients underwent surgery for bile duct exploration and T-tube replacement. Another patient developed perforation during precut sphincterotomy, and a stent was placed in the CBD and followed up. Another patient with known coronary artery disease and renal failure developed a cardiac arrest during the procedure, as a result of which the procedure was canceled. (The results of sphincterotomy are given in the Figure 1.)

Pancreatitis developed in 12 of the 1794 patients (0.66\%) whose primary cannulation was successful. However, only two of the 160 patients $(1.25 \%)$ who underwent precut sphincterotomy developed pancreatitis postoperatively. One of these two patients had undergone unsuccessful precut trials.

We began the cannulation attempt by performing precut in $160(8.2 \%)$ and using the classical approach with standard sphincterotome and guidewire in 1794 (91.8\%) patients.

The post-procedural recovery period usually took 1-2 days after ERCP, whereas it took 7-12 days in the patients requiring surgical interventions to achieve biliary access. Post-operative morbidity and mortality rates were consistent with the other studies in the literature. The cases with mortality and severe morbidity were not included in the study. Overall, there were seven mortalities unrelated to the ERCP procedure and one ERCP-related mortality.

\section{Discussion}

Early use of precut sphincterotomy has been suggested as an approach to prevent excessive and repetitive papillary trauma which may, in turn, increase the risk of post-ERCP pancreatitis. A few randomized controlled trials attempting to assess the differences in the complication rates between early precut sphincterotomy and persistent cannulation groups have shown varying results and are limited by small sample size, and therefore, inadequate to demonstrate any potential differences between the groups. ${ }^{[11]}$ The likelihood of a successful cannulation is af- 


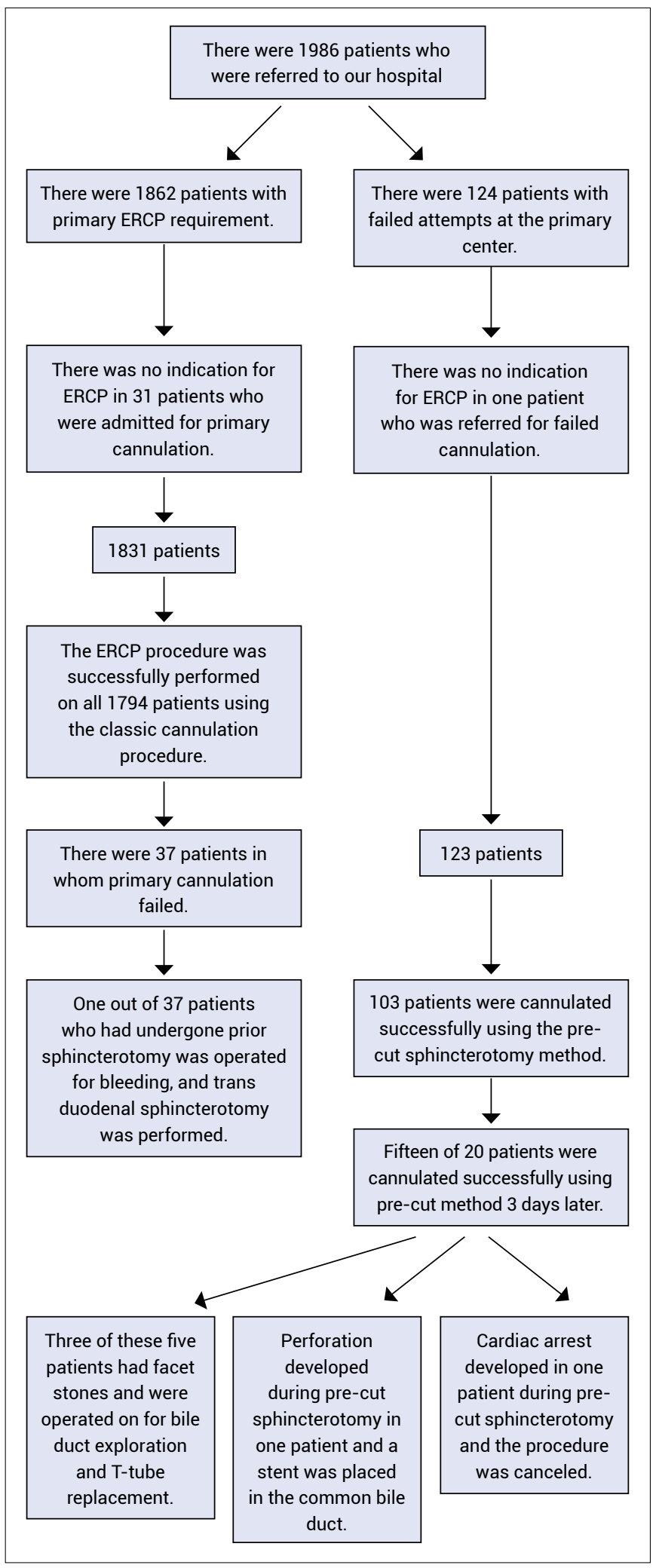

Figure 1. Classical cannulation and pre-cut sphincterotomy procedure results.

fected by operator factors (experience) and patient factors (anatomy). Both the anatomy of the papilla and anatomical variants may also cause the cannulation procedure to be challenging.
If one (or more than one) of the following indications is present:

1. Severely edematous and swollen papilla (Fig. 2)

2. Long and mobile papilla (Fig. 3)

3. Small and obscure papilla (Fig. 4)

4. Ectopic papilla (Fig. 5)

5. Tumor infiltration of the papilla (Fig. 6)

6. Intra-diverticular or peri-diverticular papilla (Fig. 7), then, ERCP can be considered a failed ERCP. ${ }^{[12-15]}$

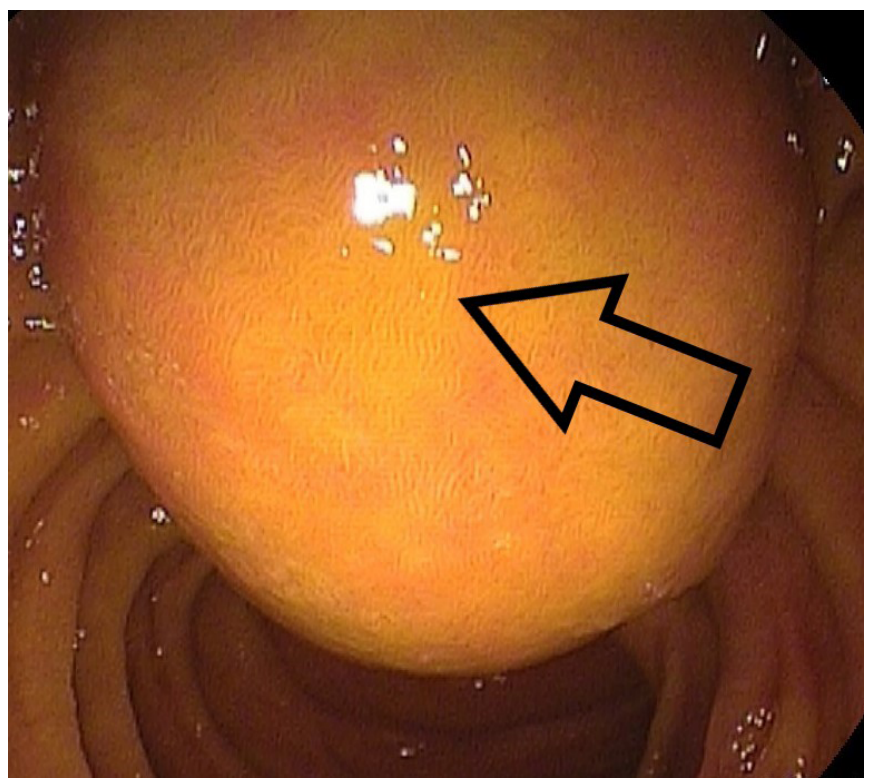

Figure 2. Severely edematous and swollen papilla.

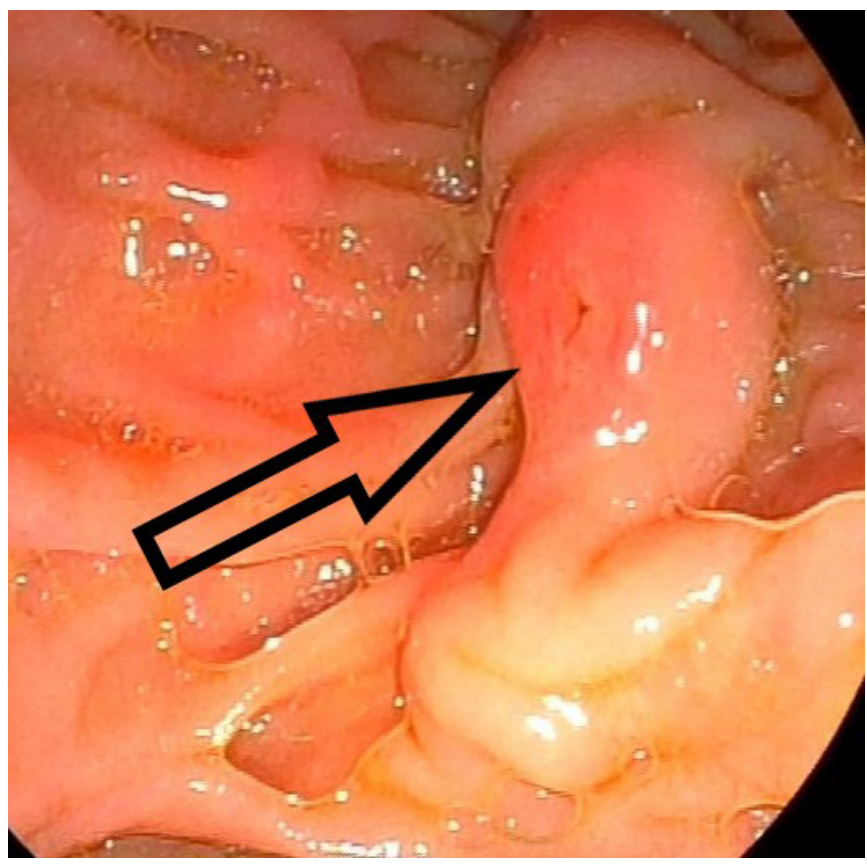

Figure 3. Long and mobile papilla 


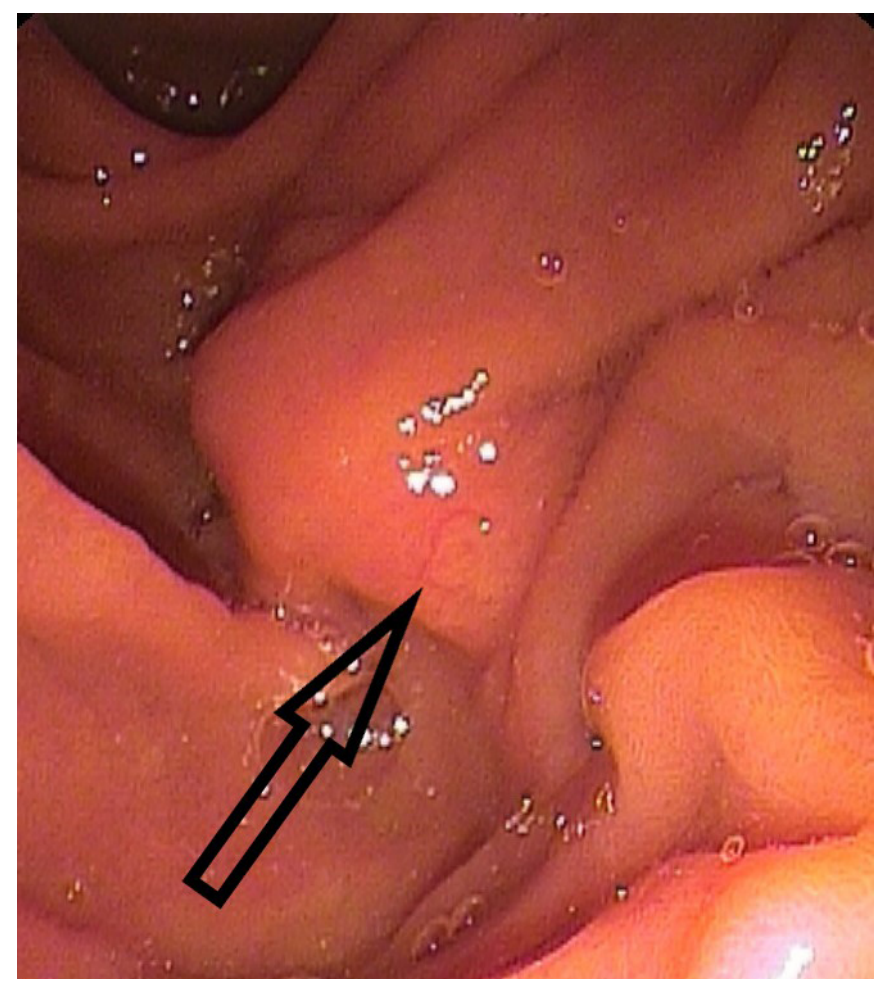

Figure 4. Small and obscure papilla.

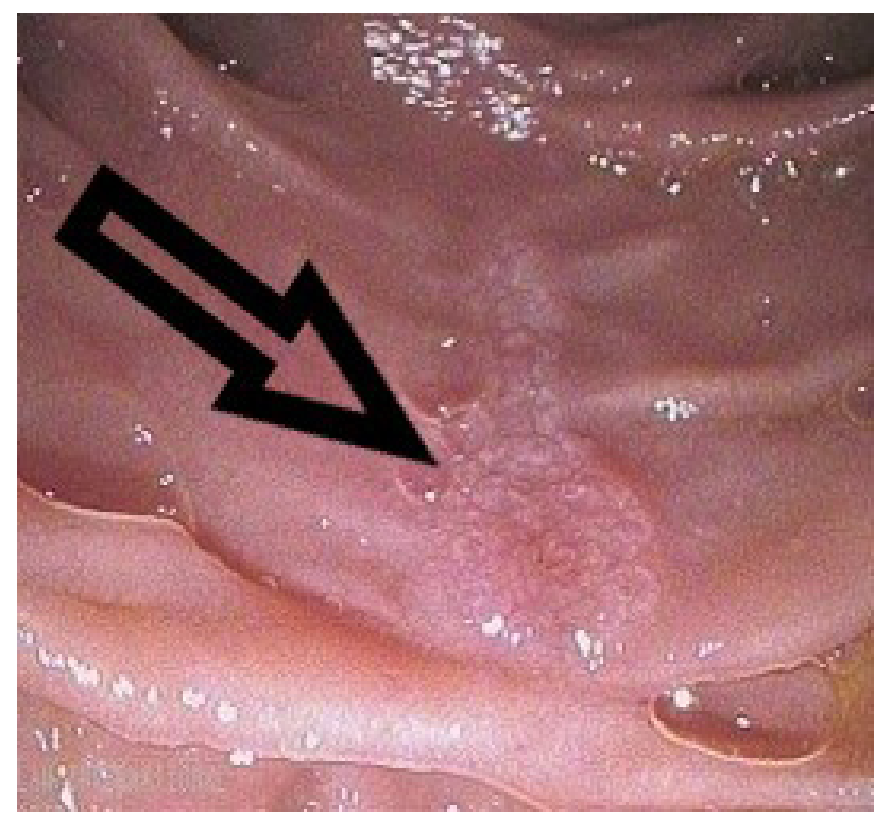

Figure 5. Ectopic papilla.

Cannulation is generally not possible on the first attempt in patients who fail the ERCP prerequisites. In such cases, the second attempt may be precut sphincterotomy (Fig. 8). However, some guidelines are needed to reduce the risk of perforation. To achieve maximum effectiveness, the endoscopist should consider the following steps after a failed cannulation attempt: (1) Describe the anatomy of the papilla and characterize it (floppy, flat, mobile, ob-

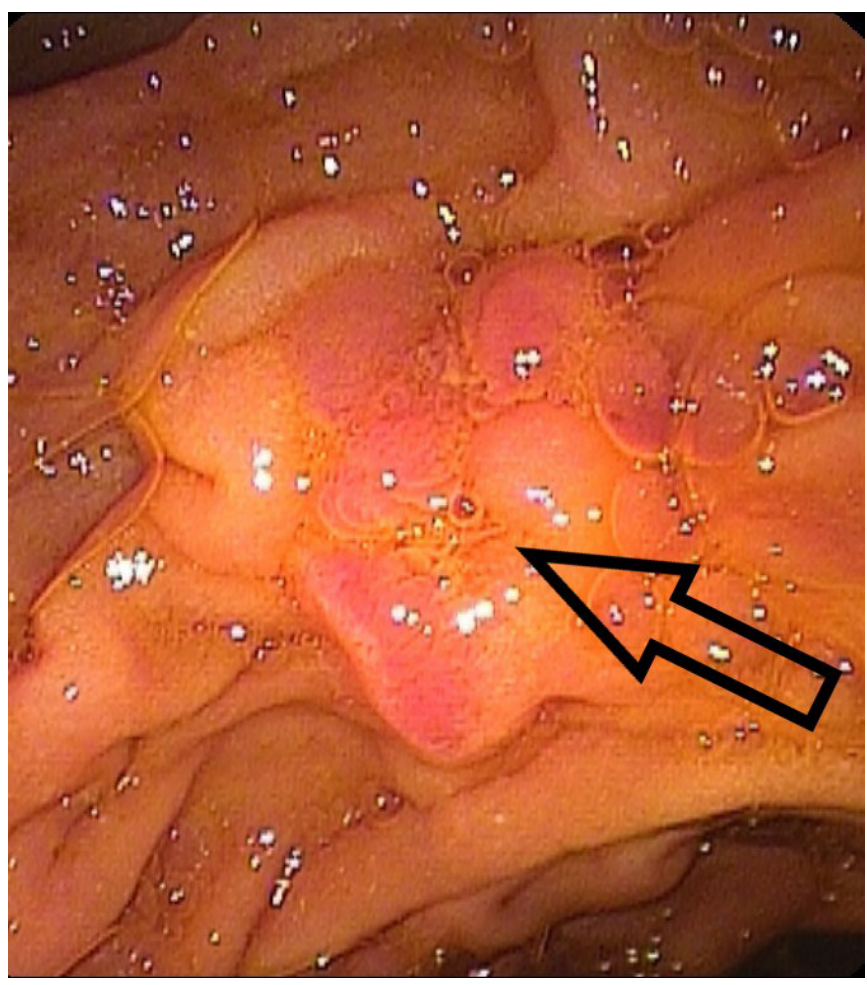

Figure 6. Tumor infiltration of the papilla.

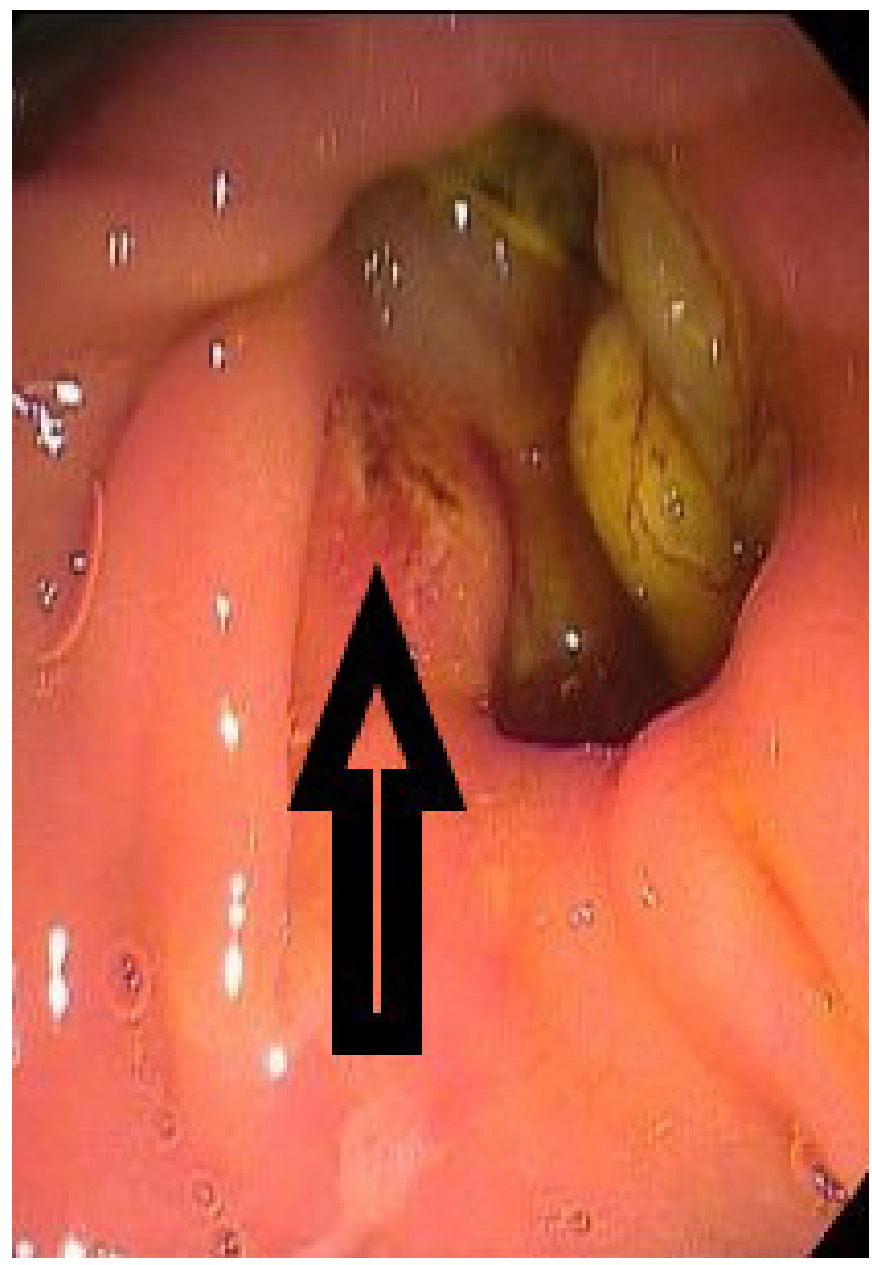

Figure 7. Intradiverticular or peridiverticular papilla. 


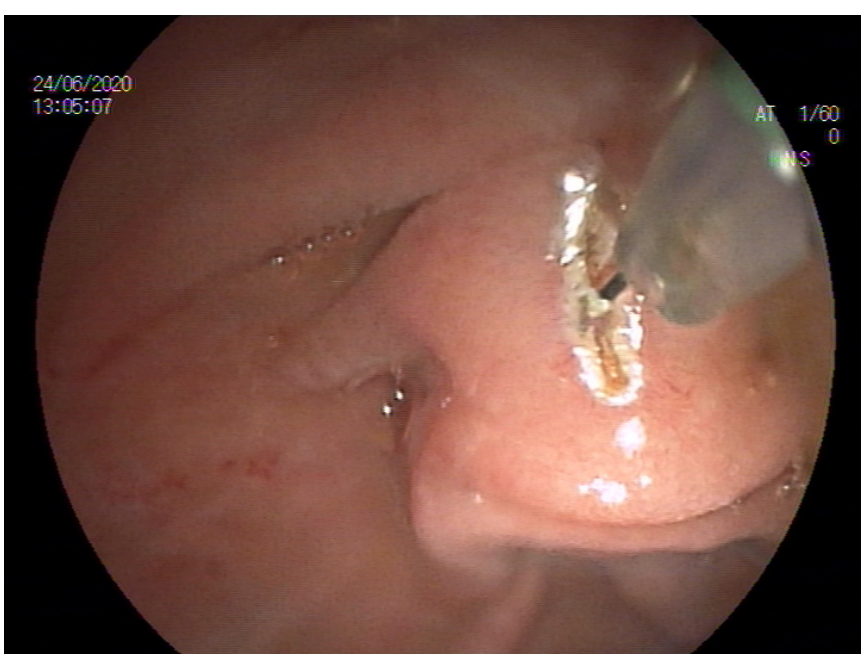

Figure 8. Reaching the common bile duct by cutting the mucosa step by step with a needle knife from the papilla roof.

scure, and swollen), (2) describe the mucosa overlying the channel and make an incision over the mucosa to expose the superior border of the bile duct, (3) describe the bile duct and perforate it until observing the bile stained flow, and (4) continue the procedure with standard sphincterotome and guidewire. ${ }^{[6]}$

Swan et al. ${ }^{[16]}$ reported that, in cases of cannulation failure, referral to experienced, high-volume, tertiary centers resulted in a high success rate and a better outcome for patients. In the present study, 47 patients were referred from other hospitals following a failed ERCP, 46 of whom were cannulated successfully at the second attempt at our center. Hence, we suggest referring patients to a tertiary center after a failed attempt.

The cannulation rate depends on experience, the center where the procedure is carried out, the anatomical structure of the papilla, the indication for ERCP, and the use of precut incision. Several authors have reported different rates of successful biliary cannulations from the community and tertiary centers, noting that higher rates could be achieved (up to 98\%) in specialized experienced hospitals which reflects an annual volume of over 500 cases and frequent use of advanced techniques. ${ }^{[17-20]}$

In this study, we found it appropriate to start with the precut approach in 160 patients with a failed cannulation. With the liberal use of the precut technique, we could not perform cannulation in only 5 of 160 patients with a papillary structure with an indication for failed ERCP. Our cannulation rate in challenging ERCP is $96.25 \%$, which is higher than the rate reported in the literature. We think that the high cannulation rate is proportional to the use of precursors liberally at the beginning of ERCP. The term "early definitive" refers to initiating cannulation interventions by cutting the papillary mucosa in selected cases rather than repeated interventions of the classical sphincterotome. Mostly, the needle-knife is provided by the sphincterotome. However, the precut procedure should be performed by endoscopists with a volume of over 500 cases and preferably experienced in tertiary centers. Several studies have reported that $10-55 \%$ of patients required precut papillotomy for cannulation. ${ }^{[21]}$

Some studies have reported that precut is an independent risk factor for ERCP-related complications. When the complications associated with the use of precut sphincterotomy were analyzed, we found perforation in one patient, bleeding in one patient, and pancreatitis after challenging ERCPs in two patients. However, our experiences have taught us that the precut procedure causes its complications, if it is used as a last resort after prolonged attempts in biliary cannulation. Hence, we begin the cannulation procedure directly with a precut incision in selected cases in which the papilla has specific features. We are of the opinion that the early use of precut sphincterotomy is not only a factor increasing the success rate but also a safe and effective procedure, as suggested by others. ${ }^{[22,23]}$

There is still a failure rate up to $15 \%$ in some series even for experienced endoscopists despite all the techniques and methods described previously. Patients are defined as "failed" if biliary access cannot be established following a reliable period or up to three unintended cannulations of the pancreatic duct. Although there is no generally accepted time limit defining a "failure," some studies have specified the time as up to $20 \mathrm{~min} .{ }^{[24]}$ Failure is a severe problem for patients and endoscopists, and there is no consensus on what should be done following a failed procedure. The possible reasons for failure are long and mobile papilla, unstable position, small papilla, and the presence of duodenal diverticula. Following a failed cannulation attempt, the endoscopist should consider other alternatives and plan treatment management. ${ }^{[25]}$

The therapeutic options following a failed ERCP procedure are repeating endoscopic attempts, percutaneous cholangiography, EUS-guided bile duct puncture, and surgical management. Since radiological techniques have complication risks in about $20-30 \%$ of the cases, repeating the procedure in a short interval seems to be encouraging. ${ }^{[26]}$ According to our department's policy, following an unsuccessful ERCP procedure, we wait for 3 days before 
repeating the procedure. We had 160 patients in whom ERCP failed initially, and 145 of them were cannulated successfully 3 days after the first attempt. After 3 days, 15 patients in whom the cannulation was unsuccessful re-underwent ERCP, and nine patients were successfully cannulated by the precut sphincterotomy.

We believe that a 3-day interval period is enough for the resorption of tissue edema, maturation of the orifice, and clarification of the tissue plans. The success rate of the second attempt for biliary cannulation by the precut sphincterotomy was $90.6 \%$ (145/160). The successful cannulation rate at the end of the third attempt was $96.25 \%$ (154/160). Therefore, it seems beneficial to repeat the ERCP procedure in a short interval following the first failed attempt once the inflammation resolved.

\section{Conclusion}

Failure in challenging ERCP procedures remains a problem. After 3-day edema reduction intervals, the repetition of the ERCP procedure with the early precut method increases the cannulation ratef; the ufe of liberal precut doef not increafe the complication ratef, and we need to pay attention to the cannulation ftepf.

\section{Disclosures}

Ethichf Committee Approval: Ethicf committee approval waf received by Afyonkarahifar Health Sciencef Univerfity Clinical Refearch Ethicf Committee by 2011-KAEK-2 on February 5, 2021 with meeting number 2021/2.

Peer-review: Externally peer-reviewed.

Conflict of Intereft: None declared.

Authorfhip Contributionf: Concept - T.A.; Defign M.B.K.; Supervifion - S.Y.; Materialf - M.B.K.; Data collection and/or proceffing - S.Y.; Analyfif and/ or interpretation - M.B.K.; Literature search - T.A.; Writing - T.A.; Critical review - S.Y.

\section{References}

1. Spicak J, Hucl T. Perfect of failed ERCP. What makes the difference. Gastroenterology 2015;4:108-13.

2. Johnson KD, Perisetti A, Tharian $B$, Thandassery $R$, Jamidar $P$, Goyal $\mathrm{H}$, et al. Endoscopic retrograde cholangiopancreatography-related complications and their management strategies: A "scoping"literature review. Dig Dis Sci 2020;65:36175. [CrossRef]

3. Chen Q, Jin P, Ji X, Du H, Lu J. Management of difficult or failed biliary access in initial ERCP. A review of current literature.
Clin Res Hepatol Gastroenterol 2019;43:365-72. [CrossRef]

4. Manes G, Paspatis G, Aabakken L, Anderloni A, Arvanitakis M, Ah-Soune $P$, et al. Endoscopic management of common bile duct stones: European society of gastrointestinal endoscopy (ESGE) guideline. Endoscopy 2019;51:472-91. [CrossRef]

5. Lee TH, Hwang SO, Choi HJ, Jung Y, Cha SW, Chung IK, et al. Sequential algorithm analysis to facilitate selective biliary access for difficult biliary cannulation in ERCP. A prospective clinical study. BMC Gastroenterol 2014;14:30. [CrossRef]

6. Colan-Hernandez J, Aldana A, Concepción M, Chavez K, Gómez C, Mendez-Bocanegra A, et al. Optimal timing for a second ERCP after failure of initial biliary cannulation following precut sphincterotomy: An analysis of experience at two tertiary centers. Surg Endosc 2017;31:3711-7. [CrossRef]

7. Pavlides M, Barnabas A, Fernandopulle N, Bailey AA, Collier J, Phillips-Hughes J, et al. Repeat endoscopic retrograde cholangiopancreaticography after failed initial precut sphincterotomy for biliary cannulation. World J Gastroenterol 2014;20:13153-8. [CrossRef]

8. Tanisaka Y, Ryozawa S, Mizuide M, Harada M, Fujita A, Ogawa $\mathrm{T}$, et al. Analysis of the factors involved in procedural failure: Endoscopic retrograde cholangiopancreatography using a short-type single-balloon enteroscope for patients with surgically altered gastrointestinal anatomy. Dig Endosc 2019;31:682-9. [CrossRef]

9. Chen $\mathrm{YI}$, Callichurn K, Chatterjee A, Desilets E, Fergal D, Forbes N, et al. ELEMENT TRIAL: Study protocol for a randomized controlled trial on endoscopic ultrasound-guided biliary drainage of first intent with a lumen-apposing metal stent vs. endoscopic retrograde cholangio-pancreatography in the management of malignant distal biliary obstruction. Trials 2019;20:696. [CrossRef]

10. Yang MJ, Kim JH, Hwang JC, Yoo BM, Kim SS, Lim SG, et al. Usefulness of combined percutaneous-endoscopic rendezvous techniques after failed therapeutic endoscopic retrograde cholangiography in the era of endoscopic ultrasound guided rendezvous. Medicine (Baltimore) 2017;96:e8991.

11. Tang SJ, Haber GB, Kortan P, Zanati S, Cirocco M, Ennis M, et al. Precut papillotomy versus persistence in difficult biliary cannulation: A prospective randomized trial. Endoscopy 2005;37:58-65. [CrossRef]

12. Haraldsson $E$, Kylänpää $L$, Grönroos J, Saarela $A$, Toth $E$, Qvigstad G, et al. Macroscopic appearance of the major duodenal papilla influences bile duct cannulation: A prospective multicenter study by the Scandinavian Association for Digestive Endoscopy Study Group for ERCP. Gastrointest Endosc 2019;90:957-63. [CrossRef]

13. Krutsri C, Kida M, Yamauchi H, Iwai T, Imaizumi H, Koizumi W. Current status of endoscopic retrograde cholangiopancreatography in patients with surgically altered anatomy. World J Gastroenterol 2019;25:3313-33. [CrossRef]

14. Niu F, Liu YD, Chen RX, Niu YJ. Safety and efficacy of enhanced recovery after surgery in elderly patients after therapeutic endoscopic retrograde cholangiopancreatography. Wideochir Inne Tech Maloinwazyjne 2019;14:394-400. [CrossRef] 
15. Ismail S, Udd M, Lindström O, Rainio M, Halttunen J, Kylänpää L. Criteria for difficult biliary cannulation: Start to count. Eur J Gastroenterol Hepatol 2019;31:1200-5. [CrossRef]

16. Swan MP, Bourke MJ, Williams SJ, Alexander S, Moss A, Hope $\mathrm{R}$, et al. Failed biliary cannulation: Clinical and technical outcomes after tertiary referral endoscopic retrograde cholangiopancreatography. World J Gastroenterol 2011;17:4993-8.

17. Cardenas A, Fernandez-Esparach G. Precut papillotomy for access into te bile duct. Video $\mathrm{J}$ Encyclopedia GI Endosc 2013;1:520-2. [CrossRef]

18. Williams EJ, Taylor S, Fairclough P, Hamlyn A, Logan RF, Martin D, et al. Are we meeting the standards set for endoscopy? Results of a large-scale prospective survey of endoscopic retrograde cholangio-pancreatograph practice. Gut 2007;56:821-9. [CrossRef]

19. Kaffes AJ, Bourke MJ, Ding S, Alrubaie A, Kwan V, Williams SJ. A prospective, randomized, placebo-controlled trial of transdermal glyceryl trinitrate in ERCP. effects on technical success and post-ERCP pancreatitis. Gastrointest Endosc 2006;64:351-7. [CrossRef]

20. Laasch HU, Tringali A, Wilbraham L, Marriott A, England $\mathrm{RE}$, Mutignani $\mathrm{M}$, et al. Comparison of standard and steerable catheters for bile duct cannulation in ERCP. Endoscopy 2003;35:669-74. [CrossRef]

21. de Weerth A, Seitz U, Zhong Y, Groth S, Omar S, Papageor- giou $\mathrm{C}$, et al. Primary precutting versus conventional overthe-wire sphincterotomy for bile duct access: A prospective randomized study. Endoscopy 2006;38:1235-40. [CrossRef]

22. Cennamo V, Fuccio L, Zagari RM, Eusebi LH, Ceroni L, Laterza $L$, et al. Can early precut implementation reduce endoscopic retrograde cholangiopancreatography-related complication risk? Meta-analysis of randomized controlled trials. Endoscopy 2010;42:381-8. [CrossRef]

23. Gong B, Hao L, Bie L, Sun B, Wang M. Does precut technique improve selective bile duct cannulation or increase postERCP pancreatitis rate? A meta-analysis of randomized controlled trials. Surg Endosc 2010;24:2670-80. [CrossRef]

24. Takahashi K, Nihei T, Aoki Y, Nakagawa M, Konno N, Munakata A, et al. Efficacy and safety of therapeutic endoscopic retrograde cholangiopancreatography in patients with native papillae with a performance status score of 3 or 4 : A single-center retrospective study. J Rural Med 2019;14:226-30.

25. Birkmeyer JD, Stukel TA, Siewers AE, Goodney PP, Wennberg $D E$, Lucas FL. Surgeon volume and operative mortality in the United States. N Engl J Med 2003;349:2117-27. [CrossRef]

26. Yamauchi $H$, Kida M, Imaizumi H, Okuwaki K, Miyazawa S, Iwai $\mathrm{T}$, et al. Innovations and techniques for balloon-enteroscope-assisted endoscopic retrograde cholangiopancreatography in patients with altered gastrointestinal anatomy. World J Gastroenterol 2015;21:6460-9. [CrossRef] 